\title{
Surgical treatment of a thoracic ventral intradural arachnoid cyst associated with syringomyelia: case report
}

\author{
Shoichi Haimoto, MD, PhD, ${ }^{1,2}$ Yusuke Nishimura, MD, $\mathrm{PhD},{ }^{2}$ and \\ Howard J. Ginsberg, MD, PhD, FRCSC1
}

\begin{abstract}
'Division of Neurosurgery, St. Michael's Hospital, University of Toronto, Ontario, Canada; and 2Department of Neurosurgery, Nagoya University Graduate School of Medicine, Nagoya, Japan
\end{abstract}

\begin{abstract}
The pathogenesis of thoracic ventral intradural spinal arachnoid cyst (ISAC) is unknown due to its extremely low incidence. In addition, its surgical treatment is complicated because of the ventral location, large craniocaudal extension, and frequent coexistence of syringomyelia. The optimal surgical strategy for thoracic ventral ISAC remains unclear and continues to be a matter of debate. In this report, the authors describe an extremely rare case presenting with a compressive thoracic ventral ISAC associated with syringomyelia that was successfully treated with a simple cystpleural shunt. The patient's medical history revealed bacterial spinal meningitis along with an extensive spinal epidural abscess, suggesting the incidence of extensive adhesive arachnoiditis (AA) to be a plausible cause for this pathology. Thoracic ventral ISAC reportedly occurs secondary to AA and is commonly associated with syringomyelia. Placement of a cyst-pleural shunt is an effective, safe, and uncomplicated surgical strategy, which can provide sufficient cyst drainage regardless of the coexistence of $A A$, and thus should be considered as primary surgical treatment. Syrinx drainage could be reserved for a later attempt in case the cyst-pleural shunt fails to reduce the extent of syringomyelia.
\end{abstract}

https://thejns.org/doi/abs/10.3171/2018.8.SPINE18223

KEYWORDS intradural spinal arachnoid cyst; syringomyelia; arachnoiditis; thoracic spine; ventral; cyst-pleural shunt

I NTRADURAL spinal arachnoid cyst (ISAC) is an uncommon cause of compressive myelopathy, which mostly arises on the dorsal aspect of the thoracic cord.,19 Ventral presentation of a thoracic ISAC is extremely rare, and therefore the pathogenesis of thoracic ventral ISAC is unknown. In this paper we report a case presenting with a compressive thoracic ventral ISAC associated with syringomyelia that was successfully treated by cyst-pleural shunt. We also discuss the pathogenesis of thoracic ventral ISAC and its optimal surgical strategy.

\section{Case Report}

History and Examination

A 56-year-old woman was admitted to our hospital in 2014 presenting with left upper-extremity weakness, gait disturbance, and urinary incontinence. She also had developed neck and lower back pain. MRI of the spine demonstrated leptomeningeal enhancement, as well as an extensive epidural collection from the cervical to the thoracic spine (Fig. 1). She underwent a lumbar puncture, from which frank pus was aspirated. Cultures from the aspirate grew methicillin-susceptible Staphylococcus aureus. Blood cultures were negative. The patient also underwent an echocardiogram that showed no evidence of infectious endocarditis. Cloxacillin was administered intravenously for 8 weeks based on the diagnosis of bacterial meningitis, along with a spinal epidural abscess. Her neurological symptoms significantly improved, and eventually cloxacillin was discontinued after completing a total duration of 16 weeks of antibiotic therapy. However, 2 years later, she was readmitted to our hospital presenting with a 4-month history of progressive gait disturbance and urinary incontinence.

On admission, neurological examination showed hypoesthesia below T4, bilateral lower-extremity numbness, right-sided lower-extremity weakness (power grade $4 / 5$ distally), and spastic gait. The patient was ambulatory with the aid of a walker. MRI of the spine demonstrated a compressive ventral ISAC at T4-9 and a large syrinx extending 

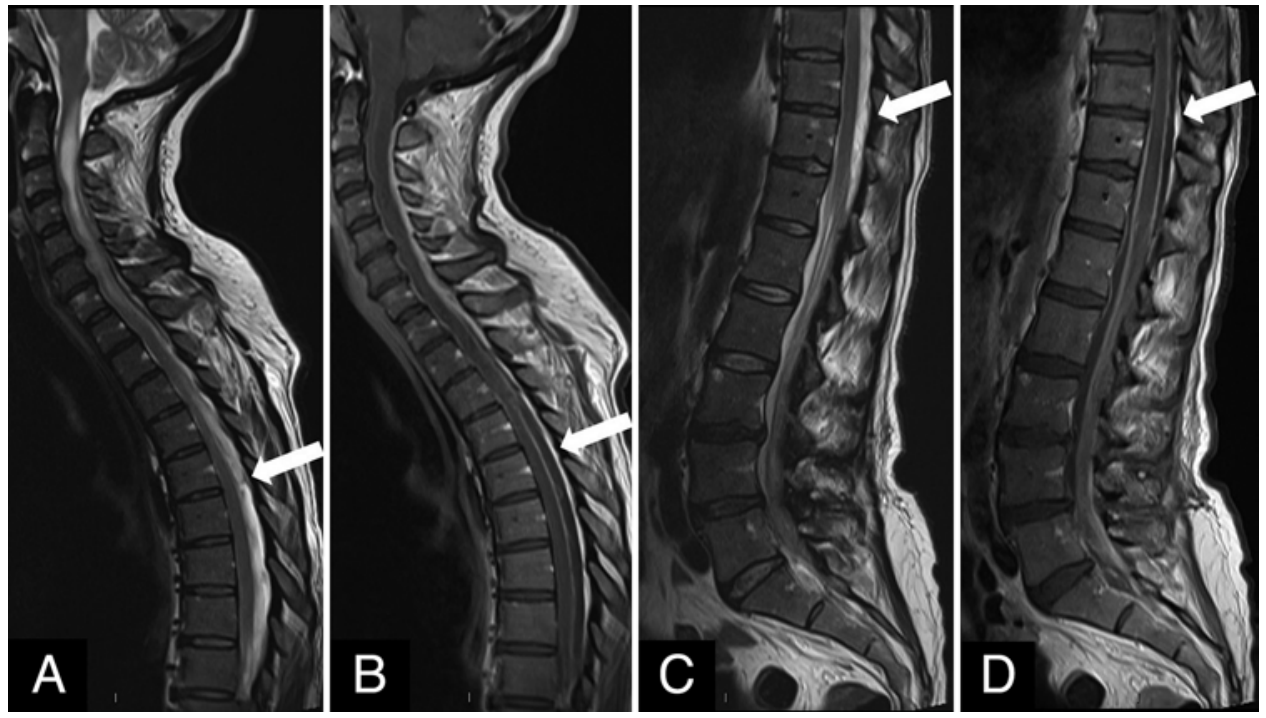

FIG. 1. Sagittal T2-weighted (A and C) and T1-weighted with contrast (B and D) MR images obtained in 2014, demonstrating diffuse leptomeningeal enhancement of the spinal cord and cauda equina associated with edema of the cervical cord, as well as a dorsal epidural fluid collection at the thoracic region (arrows).

caudally at T9-11 (Fig. 2). Spinal cord edema was found throughout the thoracic spinal cord, suggesting the coexistence of adhesive arachnoiditis (AA) presumably induced by previous meningitis, while the dorsal epidural abscess had resolved (Fig. 3A and B).

\section{Operation}

Posterior laminectomy at $\mathrm{T} 6$ followed by insertion of a cyst-pleural shunt (Medtronic) was performed to release the pressure of the ventral ISAC as well as to potentially restore the CSF circulation. With the patient prone, a midline incision was made and the paraspinal muscles were dissected more extensively on the left to expose the costovertebral joint of T7. A standard laminectomy at T6 was performed using a rongeur. Upon opening of the dura, dense arachnoid adhesion was identified, confirming the coexistence of AA. A short, direct T-tube catheter (Medtronic) was inserted into the ventral ISAC after
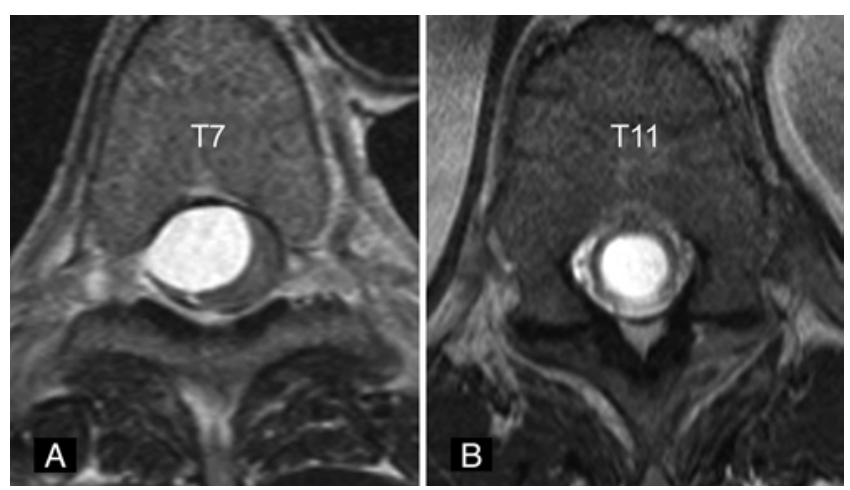

FIG. 2. A: Preoperative axial T2-weighted MR image at T7 showing a ventral intradural extramedullary cystic mass compressing the spinal cord. B: Preoperative axial T2-weighted MR image at T11 showing a massive intramedullary cystic lesion. puncture of the cyst. Cyst wall excision was minimized to prevent tube migration. The distal tip of the catheter was implanted into the pleural cavity at a site immediately lateral to the costovertebral joint of $\mathrm{T} 7$.

\section{Postoperative Course}

There were no surgical complications. At the 7-month postoperative follow-up, neurological symptoms had completely resolved and the patient could walk without assistance. MRI obtained 7 months after surgery demonstrated significant reduction in both the ventral ISAC and syringomyelia, leading to sufficient decompression of the spinal cord, although cord edema had persisted due to extensive AA (Fig. 3C and D).

\section{Discussion}

To the best of our knowledge, this is the first case report describing a thoracic ventral ISAC associated with syringomyelia successfully treated by a cyst-pleural shunt.

As ISACs mostly arise on the dorsal aspect of the thoracic cord, ${ }^{1,19}$ the pathogenesis of a thoracic ventral ISAC is not well known. It has been postulated that an ISAC could occur as either a primary lesion or a secondary pathology associated with AA as a consequence of trauma, subarachnoid hemorrhage, meningitis, intrathecal injection, or intradural surgery. .,5, , $, 10,12-16,21$ Perret et al. reported that primary dorsal ISAC unassociated with AA arises from the layers of septum posticum, ${ }^{17}$ but anatomically this mechanism is not applicable in ventral ISACs. Moreover, thoracic ventral ISAC is reportedly different from dorsal ISAC in having greater craniocaudal extension and showing intracystic fibrous septae, suggesting that ventral presentation of thoracic ISAC is likely to occur secondary to AA. ${ }^{18}$ Klekamp reported surgical outcomes of a large series of ISACs, with only 21 (16\%) of 130 cases presenting as secondary ISACs. They discussed that primary 

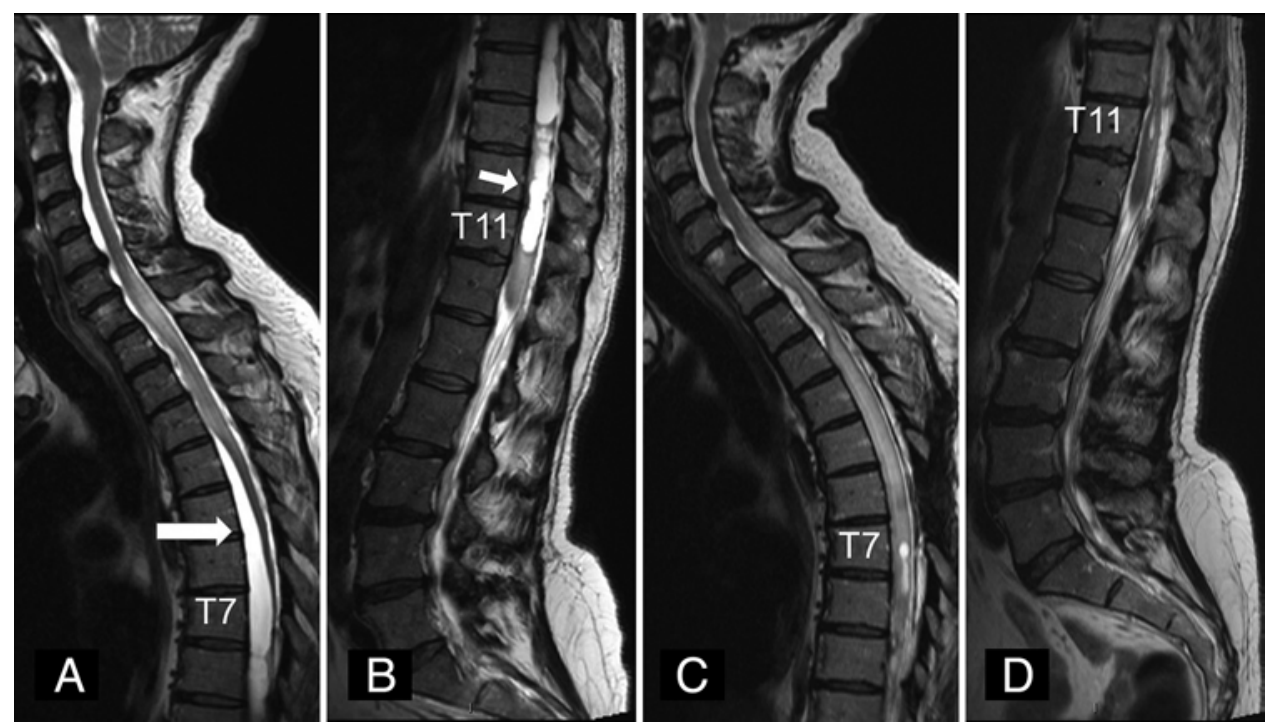

FIG. 3. A and B: Preoperative sagittal T2-weighted MR images demonstrating a ventral intradural extramedullary arachnoid cyst at T4-9 (long arrow) and syrinx formation at T9-11 (short arrow). C and D: Postoperative sagittal T2-weighted MR images confirming the disappearance of the arachnoid cyst as well as significant reduction in the size of the syrinx.

ISACs were all located in the dorsal aspect of the spinal cord, mostly thoracic, while secondary ISACs were encountered in a more ventral position in relation to the spinal cord. ${ }^{12}$ As far we know, there are only 7 cases reported in the literature (including the present case) describing the etiology and surgical outcomes of thoracic ventral ISACs associated with syringomyelia ${ }^{6,7,18,23}$ (Table 1). Most importantly, 4 (57\%) of 7 patients had clear histories of spinal pathology that could plausibly explain the coexistence of AA such as meningitis, trauma, or intrathecal injection. AA was considered to be the main pathogenesis of thoracic ventral ISAC in these 4 cases. In addition, all thoracic ventral ISACs were associated with syringomyelia extending either cranially or caudally in proximity to ISACs. It has been discussed in the literature that ISAC itself may cause alternations in CSF flow within the subarachnoid space, resulting in syrinx formation..$^{8,20}$ With respect to secondary ISACs associated with AA, the coexistence of AA could be an additional contributing factor for syrinx formation leading to a high incidence of syringomyelia. In fact, a recent study found that secondary ISACs are much more commonly associated with syringomyelia than primary ISACs. ${ }^{12}$ Based on these findings, it should be acknowledged that thoracic ventral ISACs appear to occur secondary to AA and are commonly associated with syringomyelia. A patient presenting with a thoracic ventral ISAC should be carefully reviewed for any previous spinal pathology such as trauma, subarachnoid hemorrhage, meningitis, intrathecal injection, or intradural surgery to detect the underlying nature of the disease.

In the present case, diagnosis was based on preoperative MRI with intraoperative ultrasound confirmation. Preop-

TABLE 1. Summary of surgically treated thoracic ventral ISACs associated with syringomyelia

\begin{tabular}{|c|c|c|c|c|c|c|c|c|c|c|c|}
\hline \multirow[b]{2}{*}{ Authors \& Year } & \multirow{2}{*}{$\begin{array}{c}\text { Age } \\
\text { (yrs), } \\
\text { Sex }\end{array}$} & \multirow{2}{*}{$\begin{array}{l}\text { History of Spinal } \\
\text { Pathology }\end{array}$} & \multirow{2}{*}{$\begin{array}{c}\text { Cyst } \\
\text { Classification }\end{array}$} & \multicolumn{2}{|c|}{ Lesion Levels } & \multirow[b]{2}{*}{ Tx for ISAC } & \multirow{2}{*}{$\begin{array}{l}\text { Syrinx } \\
\text { Shunt }\end{array}$} & \multirow{2}{*}{$\begin{array}{l}\text { Postop } \\
\text { FU }\end{array}$} & \multirow{2}{*}{$\begin{array}{l}\text { Neurological } \\
\text { Improvement }\end{array}$} & \multicolumn{2}{|c|}{$\begin{array}{l}\text { Radiological } \\
\text { Improvement }\end{array}$} \\
\hline & & & & ISAC & Syrinx & & & & & ISAC & Syrinx \\
\hline \multirow[t]{3}{*}{ Wang et al., 2003} & $54, \mathrm{M}$ & None & Primary & T3-4 & NA & Fenestration & Yes & 10 mos & Unchanged & Yes & Yes \\
\hline & $35, M$ & None & Primary & $\mathrm{T} 7-10$ & NA & $\begin{array}{l}\text { Cyst-subarachnoid } \\
\text { shunt }\end{array}$ & No & 10 mos & Resolved & Yes & Yes \\
\hline & $67, \mathrm{M}$ & None & Primary & T7-8 & NA & Fenestration & No & $11 \mathrm{mos}$ & Resolved & Yes & Yes \\
\hline $\begin{array}{l}\text { Gnanalingham et } \\
\text { al., } 2006\end{array}$ & $62, F$ & $\begin{array}{l}\text { Myelogram w/ } \\
\text { Myodil }\end{array}$ & Secondary & T10-12 & T6-8 & $\begin{array}{l}\text { Cyst-subarachnoid } \\
\text { shunt }\end{array}$ & Yes & $1 \mathrm{yr}$ & $\begin{array}{l}\text { Partially } \\
\text { improved }\end{array}$ & NA & NA \\
\hline $\begin{array}{l}\text { Peruzzotti-Jametti } \\
\text { et al., } 2010\end{array}$ & $53, M$ & $\begin{array}{l}\text { Craniocervical } \\
\text { trauma }\end{array}$ & Secondary & $\mathrm{C} 1-\mathrm{T} 11$ & $\mathrm{C} 1-2$ & $\begin{array}{l}\text { Cyst-subarachnoid } \\
\text { shunt }\end{array}$ & No & $1 \mathrm{yr}$ & Deteriorated & No & No \\
\hline Hirai et al., 2012 & $29, F$ & $\begin{array}{l}\text { Spinal \& epidural } \\
\text { anesthesia }\end{array}$ & Secondary & C7-T6 & $\begin{array}{c}\text { Below } \\
\text { T6 }\end{array}$ & $\begin{array}{l}\text { Cyst-peritoneal } \\
\text { shunt }\end{array}$ & No & $3 \mathrm{yrs}$ & $\begin{array}{l}\text { Partially } \\
\text { improved }\end{array}$ & Yes & No \\
\hline Present case & $58, F$ & Meningitis & Secondary & T4-9 & T9-11 & Cyst-pleural shunt & No & $7 \mathrm{mos}$ & Resolved & Yes & Yes \\
\hline
\end{tabular}

$\mathrm{FU}=$ follow-up; $\mathrm{NA}=$ not applicable; $\mathrm{Tx}=$ treatment. 
erative neuroimaging options used in the diagnosis of ISAC include MRI and CT myelography, each of which has merits and drawbacks. For primary ISACs, the extremely thin and floating membranes may not be visible on standard MRI sequences. ${ }^{4}$ Although thin-slice scans or cardiac-gated cine MRI may be more sensitive to demonstrate their extent, it has yet to be used routinely in clinical practice.22 Furthermore, when applied in secondary ISACs, cine MRI can hardly detect any CSF flow due to extensive AA. ${ }^{12}$ On the other hand, as in the present case, whole-spine MRI may be useful to demonstrate suggestive findings of the underlying AA such as extensive cord edema, syringomyelia, or clumping of lumbar roots. CT myelography may demonstrate the intradural filling defect more effectively, but it demands an invasive and painful procedure with moderate radiation exposure to the patient. ${ }^{4}$ Moreover, for secondary ISACs, contrast filling from above and below may be required to demonstrate their extent due to the profoundly restricted CSF flow. 12

The optimal surgical strategy for thoracic ventral ISAC remains unclear. There are three types of surgical options proposed for ISACs: cyst resection, fenestration, and CSF flow diversion. ${ }^{1,8,11,23}$ In the treatment of thoracic ventral ISACs, the frequent coexistence of AA should be taken into account as it could profoundly affect surgical outcomes. To begin, complete resection of thoracic ventral ISAC is rarely possible because of its ventral location and great craniocaudal extension. Fenestration is one of the most often used and effective surgical procedures in the treatment of ISACs, particularly for primary lesions..$^{2,23}$ Wang et al. described 3 cases of idiopathic thoracic ventral ISAC associated with syringomyelia that were successfully treated by fenestration with additional syringo-subarachnoid shunting as needed..$^{23}$ Primary ISACs not associated with AA could be well managed with fenestration even if the ISAC is located on the ventral side. However, surgical outcomes are reportedly unfavorable in secondary ISACs because CSF flow in the subarachnoid space is blocked due to extensive AA where cyst fluid would be drained. In fact, a recent study reported that either cyst resection or fenestration could only provide clinical stabilization for a limited period for secondary ISACs. Progression-free survival for 10 years was determined to be $83 \%$ for primary ISACs compared to $15 \%$ for secondary ISACs..$^{12}$ Therefore, CSF flow diversion such as shunting of the cyst may be favorable as primary surgical treatment for thoracic ventral ISACs. In this respect, a cyst-subarachnoid shunt has been adopted in 2 cases of thoracic ventral ISACs. ${ }^{6}, 18$ However, PeruzzottiJametti et al. described a case resulting in shunt malfunction shown on postoperative CT myelography, concluding that a cyst-subarachnoid shunt is not effective for thoracic ventral ISACs. ${ }^{18}$ The subarachnoid space may not be optimal as the outlet of cyst drainage, considering the existence of AA. Extensive AA causes obstruction of the CSF flow within the subarachnoid space leading to malfunction of the shunt system. Other options for CSF flow diversion include draining the cyst into either the peritoneal or pleural cavity. Hirai et al. performed a cyst-peritoneal shunt insertion and accomplished radiological improvement of the ISAC, while reduction of the syrinx was limited. In the present case, a cyst-pleural shunt provided significant reduction in both the ISAC and syringomyelia, in addition to complete resolution of neurological symptoms. It is most likely that these successful surgical outcomes were brought on by the fact that both cyst-peritoneal and -pleural shunts can provide effective cyst drainage regardless of the coexistence of AA.

There are several advantages in adopting a cyst-pleural shunt insertion as the primary surgical treatment for thoracic ventral ISACs rather than a cyst-peritoneal shunt insertion. First, the negative pressure of the pleural cavity increases the drainage rate and improves the patency of the shunt system., ${ }^{3,24}$ In the present case, the increased drainage rate might have led to significant reduction in both the ISAC and syringomyelia, thus avoiding additional surgical intervention to the syrinx. Wang et al. reported that a fistula exists between the ISAC and syrinx,${ }^{23}$ therefore increasing the drainage effect may be the key factor in achieving simultaneous reduction in both the ISAC and syringomyelia. Syrinx drainage such as syringo-pleural shunt could be reserved for a later attempt in case the cystpleural shunt fails to reduce the extent of syringomyelia. Second, because of its thoracic location, the ISAC and pleural cavity could be approached via a single posterior incision and communicated using a short, direct catheter course, resulting in decreased risk of shunt failure. ${ }^{24}$ For these above-mentioned reasons, a simple cyst-pleural shunt seems to be the most effective, safe, and uncomplicated surgical procedure for secondary thoracic ventral ISACs associated with syringomyelia. Nevertheless, as this surgical strategy is not aimed to treat the underlying extensive AA, which is often an extremely challenging attempt, the patient should be followed carefully for either new-onset or recurrent ISAC and syringomyelia.

\section{References}

1. Bassiouni H, Hunold A, Asgari S, Hübschen U, König HJ, Stolke D: Spinal intradural juxtamedullary cysts in the adult: surgical management and outcome. Neurosurgery 55:13521360, 2004

2. Evangelou P, Meixensberger J, Bernhard M, Hirsch W, Kiess $\mathrm{W}$, Merkenschlager A, et al: Operative management of idiopathic spinal intradural arachnoid cysts in children: a systematic review. Childs Nerv Syst 29:657-664, 2013

3. Fan T, Zhao X, Zhao H, Liang C, Wang Y, Gai Q, et al: Treatment of selected syringomyelias with syringo-pleural shunt: the experience with a consecutive 26 cases. Clin Neurol Neurosurg 137:50-56, 2015

4. French H, Somasundaram A, Biggs M, Parkinson J, Allan R, Ball J, et al: Idiopathic intradural dorsal thoracic arachnoid cysts: A case series and review of the literature. J Clin Neurosci 40:147-152, 2017

5. Glenn CA, Bonney P, Cheema AA, Conner AK, Gross NL, Yaun AL: Iatrogenic intradural arachnoid cyst following tethered cord release in a child. J Clin Neurosci 24:163-164, 2016

6. Gnanalingham KK, Joshi SM, Sabin I: Thoracic arachnoiditis, arachnoid cyst and syrinx formation secondary to myelography with Myodil, 30 years previously. Eur Spine J 15 (Suppl 5):661-663, 2006

7. Hirai T, Kato T, Kawabata S, Enomoto M, Tomizawa S, Yoshii T, et al: Adhesive arachnoiditis with extensive syringomyelia and giant arachnoid cyst after spinal and epidural anesthesia: a case report. Spine (Phila Pa 1976) 37:E195E198, 2012 
8. Holly LT, Batzdorf U: Syringomyelia associated with intradural arachnoid cysts. J Neurosurg Spine 5:111-116, 2006

9. Ishizaka S, Hayashi K, Otsuka M, Fukuda S, Tsunoda K, Ushijima R, et al: Syringomyelia and arachnoid cysts associated with spinal arachnoiditis following subarachnoid hemorrhage. Neurol Med Chir (Tokyo) 52:686-690, 2012

10. Jean WC, Keene CD, Haines SJ: Cervical arachnoid cysts after craniocervical decompression for Chiari II malformations: report of three cases. Neurosurgery 43:941-945, 1998

11. Jensen F, Knudsen V, Troelsen S: Recurrent intraspinal arachnoid cyst treated with a shunt procedure. Acta Neurochir (Wien) 39:127-129, 1977

12. Klekamp J: A new classification for pathologies of spinal meninges - part 2: primary and secondary intradural arachnoid cysts. Neurosurgery 81:217-229, 2017

13. Kriss TC, Kriss VM: Symptomatic spinal intradural arachnoid cyst development after lumbar myelography. Case report and review of the literature. Spine (Phila Pa 1976) 22:568572,1997

14. Lesoin F, Rousseau M, Thomas CE III, Jomin M: Post traumatic spinal arachnoid cysts. Acta Neurochir (Wien) 70:227-234, 1984

15. Lolge S, Chawla A, Shah J, Patkar D, Seth M: MRI of spinal intradural arachnoid cyst formation following tuberculous meningitis. Br J Radiol 77:681-684, 2004

16. Osenbach RK, Godersky JC, Traynelis VC, Schelper RD: Intradural extramedullary cysts of the spinal canal: clinical presentation, radiographic diagnosis, and surgical management. Neurosurgery 30:35-42, 1992

17. Perret G, Green D, Keller J: Diagnosis and treatment of intradural arachnoid cysts of the thoracic spine. Radiology 79:425-429, 1962

18. Peruzzotti-Jametti L, Ferrari S, Politi LS, Snider S, Mammi $\mathrm{S}$, Comi G, et al: Giant anterior arachnoid cyst associated with syringomyelia: implications for treatment and followup. Spine (Phila Pa 1976) 35:E322-E324, 2010

19. Silbergleit R, Brunberg JA, Patel SC, Mehta BA, Aravapalli SR: Imaging of spinal intradural arachnoid cysts: MRI, myelography and CT. Neuroradiology 40:664-668, 1998
20. Takeuchi A, Miyamoto K, Sugiyama S, Saitou M, Hosoe H, Shimizu K: Spinal arachnoid cysts associated with syringomyelia: report of two cases and a review of the literature. $\mathbf{J}$ Spinal Disord Tech 16:207-211, 2003

21. Thines L, Khalil C, Fichten A, Lejeune JP: Spinal arachnoid cyst related to a nonaneurysmal perimesencephalic subarachnoid hemorrhage: case report. Neurosurgery 57:E817, 2005

22. Viswanathan VK, Manoharan SR, Do H, Minnema A, Shaddy SM, Elder JB, et al: Clinical and radiologic outcomes after fenestration and partial wall excision of idiopathic intradural spinal arachnoid cysts presenting with myelopathy. World Neurosurg 105:213-222, 2017

23. Wang MY, Levi ADO, Green BA: Intradural spinal arachnoid cysts in adults. Surg Neurol 60:49-56, 2003

24. Won DJ, Siddiqi J, Yamada S: A novel, simplified pediatric syringopleural shunt. Technical note. J Neurosurg 102 (1 Suppl):123-126, 2005

\section{Disclosures}

Dr. Ginsberg reports being a consultant to Stryker.

\section{Author Contributions}

Conception and design: Haimoto. Acquisition of data: Haimoto. Analysis and interpretation of data: Haimoto. Drafting the article: Haimoto. Critically revising the article: Ginsberg, Nishimura. Reviewed submitted version of manuscript: Ginsberg, Nishimura. Approved the final version of the manuscript on behalf of all authors: Ginsberg.

\section{Correspondence}

Howard J. Ginsberg: St. Michael's Hospital, University of Toronto, ON, Canada. ginsbergh@smh.ca. 